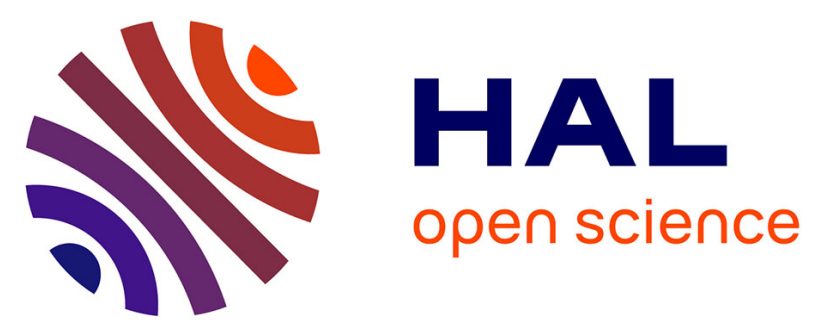

\title{
No effect of classroom sharing on educational achievement in twins: a prospective, longitudinal cohort study
}

Tinca Jc Polderman, Meike Bartels, Frank C Verhulst, Anja C Huizink, Catherina Em van Beijsterveldt, Dorret I Boomsma

\section{To cite this version:}

Tinca Jc Polderman, Meike Bartels, Frank C Verhulst, Anja C Huizink, Catherina Em van Beijsterveldt, et al.. No effect of classroom sharing on educational achievement in twins: a prospective, longitudinal cohort study. Journal of Epidemiology and Community Health, 2009, 64 (01), pp.36-n/a. 10.1136/jech.2009.091629 . hal-00490561

\section{HAL Id: hal-00490561 https://hal.science/hal-00490561}

Submitted on 9 Jun 2010

HAL is a multi-disciplinary open access archive for the deposit and dissemination of scientific research documents, whether they are published or not. The documents may come from teaching and research institutions in France or abroad, or from public or private research centers.
L'archive ouverte pluridisciplinaire HAL, est destinée au dépôt et à la diffusion de documents scientifiques de niveau recherche, publiés ou non, émanant des établissements d'enseignement et de recherche français ou étrangers, des laboratoires publics ou privés. 
RESEARCH

\section{No effect of classroom sharing on educational achievement in twins: a prospective, longitudinal cohort study}

Tinca J. C. Polderman, postdoctoral fellow ${ }^{* 1,2}$, Meike Bartels, assistant professor ${ }^{1}$, Frank C. Verhulst, psychiatrist, professor, head², Anja C. Huizink, associate professor $^{2,3}$, Catharina E. M. van Beijsterveldt, assistant professor ${ }^{1}$, and Dorret I. Boomsma, professor, head ${ }^{1}$

*to whom correspondence should be addressed

${ }^{1}$ Department of Biological Psychology, VU University Amsterdam Van der Boechorststraat 1, 1081 BT, Amsterdam, The Netherlands

Tel. 0031205986951

Fax. 0031205988832

Email: jc.polderman@psy.vu.nl

${ }^{2}$ Erasmus University Medical Center - Sophia Children's Hospital, Department of Child and Adolescent Psychiatry, Rotterdam, The Netherlands

${ }^{3}$ Department of Education, University of Amsterdam, The Netherlands

Keywords: twins, schools, educational status Word Count: 3618 


\section{ABSTRACT}

Objective: To investigate the effects of sharing a classroom during primary school on cognitive achievement in twins

Design: Prospective, longitudinal study in twins registered at birth

Setting: The Netherlands Twin Register

Participants: 839 monozygotic and 1164 dizygotic twin pairs

Main Outcome Measure: Educational achievement at age 12 years measured with a standardized test (CITO test) used by $93 \%$ of the Dutch primary schools.

Results: Most twin pairs (72\%) shared a classroom during their schooling, $19 \%$ were in separate, but parallel classes, and 9\% 'partly' shared a classroom. Twins who were in parallel classrooms had higher CITO scores (mean 539.51; sd 8.12), compared to twins who shared a classroom (537.99; sd 8.52). When controlling for socio-economic status and externalizing problems before starting primary school (age 3) there was no significant difference in educational achievement between separated and non-separated twin pairs $(P=.138)$. In addition, there was no interaction with sex or zygosity of the twins $(P=.798)$.

Conclusion: There is no difference in educational achievement between twins who share a classroom and twins who do not share a classroom during their primary school time. The choice of separation should be made by teachers, parents and their twin children, based on individual characteristics of a twin pair. 


\section{INTRODUCTION}

Being part of a twin pair has benefits like always having a friend and companion around, and being part of a unique and special relationship that is not available for singletons. Having a co-twin may, however, also have possible detriments like the inability to develop as a unique and independent individual. Families with multiple births naturally want to offer the optimal conditions in which twins can function effectively, both as multiples as well as individuals. A returning dilemma for them is whether twins should share the same, or a parallel classroom, in other words, whether they should be separated at school or not.

A survey in the UK showed that only one percent of schools had written policies about the education and management of multiple birth children. Also, the decision to separate or not, was often made by educators alone, without the input of parents. ${ }^{1}$ Most twins spent their schooling years together and $7 \%$ of schools reported they always separated twins. In the Netherlands an increasing practice of separating twins is reported ${ }^{2,3}$ while in Scandinavian countries multiples almost always share the classroom. ${ }^{4}$ Educational policies and practice -independent of a focus on sharing or separation- seem to be based on popularized stereotypic depictions of twins (in general monozygotic pairs) rather then on empirical research. ${ }^{5}$ Hay and Preedy 6 emphasize a clear and evidence based recommendation on which school policies and even ongoing legislative initiatives in the $\mathrm{USA}^{7}$ can be based, as 'teachers and parents should be aware of particular issues that may affect the physical, intellectual, personal, social, and emotional development of multiple birth children'. Given this argument and the growing multiple birth rate ${ }^{8,9}$ it is surprising that only three studies investigated whether or not classroom separation at the primary school is beneficial or detrimental for the behavioral and cognitive development of twins.

Two studies concentrated mainly on behavioral and emotional implications of the separation of twins at school ${ }^{3,10}$, and one study focused on cognitive abilities. ${ }^{11}$ 
All studies were based on rather large twin samples: a British sample of 878 twin pairs $^{10}$, a Dutch sample of 5128 twin pairs ${ }^{3}$, and a Dutch sample of 2878 twin pairs. ${ }^{11}$ Both Dutch studies (only little overlap in samples; 3.92\%) had longitudinal data covering the complete primary school period (i.e. grade 1 to 8 ), while the study of Tully et al. ${ }^{10}$ was limited to the first three years of school (age 5 to 7 ).

The major finding of the first two studies was that internalizing problems in young twins could be attributed to separation of the twins at the beginning of their schooling. However, the effects sizes were small and in the Dutch sample the effects had disappeared in grade 8 . For externalizing problems Tully et al. ${ }^{10}$ found no differences, while van Leeuwen et al. ${ }^{3}$ found an effect of separation. Externalizing problems in separated twins were explained by pre-existing differences between twins, suggesting that the externalizing problems could have been a motivation for parents and teachers to separate the twins. In addition, van Leeuwen et al. ${ }^{3}$ found that socio-economic status (SES) was significantly associated with the classroom placement of a twin pair (i.e. separated or together); families with lower SES had their twins more often placed together.

For the cognitive development of twins Webbink et al. ${ }^{11}$ found no important differences between twins sharing a classroom, or not. Their results showed a small positive effect for non-separated twins on language and arithmetic in Grade 2, but in the higher grades no effects were found. As zygositity of the twins in this study was unknown the interaction with classroom separation and zygosity was not investigated. Tully et al. ${ }^{10}$ found lower reading scores for separated twins, but this was only the case for monozygotic (MZ) twins at age 7 who were separated after one year of schooling, and this finding did not apply to twins who were separated earlier.

The current study expands on this prior work by examining the effects of classroom separation on educational achievement in a large longitudinal sample of typically developing twins (age 3 to age 12). The large sample enabled us to 
examine whether the effects of classroom separation differed for male and female, and for monozygotic (MZ) and dizygotic (DZ) twins. We used a standardized Dutch achievement test, called CITO test, which is assessed in grade 8 at $93 \%$ of the Dutch primary schools. The CITO test highly correlates with IQ performance ${ }^{12}$ and plays an important advisory role in the choice of secondary school education. Several confounding factors may bias the true association between classroom separation and the outcome measure. The following factors were taken into account: a) zygosity (MZ or DZ), b) socio-economic status, c) urbanization (as schools situated in low urbanized areas, might not offer the opportunity to separate twins because only one classroom for a specific grade is available), and d) preexisting and current externalizing problems. ${ }^{3}$

\section{METHODS}

\section{Sample}

All twins were registered with the Netherlands Twin Register (NTR), established in 1986 by the Department of Biological Psychology at the VU University in Amsterdam. Of all multiple births in the Netherlands about $50 \%$ is registered in the NTR. ${ }^{13,14}$ Data of twins from the $1986-1993$ birth cohorts were used in this study. Surveys on development, health, psychopathology and socio-demographic characteristics have been collected longitudinally at the ages of $1,2,3,5,7,10$ and 12 years. Response rates at ages 3, 7, 10 and 12 years were $72 \%, 66 \%, 64 \%$ and $64 \%$ respectively (note that if a family did not participate at a particular age, they were approached again for the next mailing) ${ }^{15}$ For this study, information from surveys completed by mothers of twins at ages 3, 5, 7, 10 and 12 years was used. 


\section{Together or separated}

The surveys sent to the mothers of twins at ages 5 and 12 years contained questions on whether the twins were in the same class. In the Netherlands, most children start primary school at the age of 4 years; compulsory education, however, starts at the age of 5 years. Nearly all children attend primary school for 8 years and go to secondary school around the age of 12 years. The separation of twin pairs can occur when children first start school or during primary school. Mothers of twins who were 12 years of age were asked 'which statement applies best to the school history of your twins' a) same school, same classroom b) same school, parallel classes (i.e., same level) c) same school, different levels d) different schools e) partly same class, partly separated. When the twins were 5 years old, the mother was asked whether 'the twins are now a) together in the same school in the same classroom b) together in the same school but not in the same classroom and c) at different schools'.

\section{Outcome measure}

Educational achievement of the twins was assessed with the Dutch CITOelementary test (Eindtoets Basisonderwijs, 2002, www.cito.nl). The CITO consists of 240 multiple-choice items assessing four different intellectual skills: Language, Mathematics, Information Processing, and World Orientation. Together the performance scales result in a standardized score between 501 and 550 . The test is usually administered on three consecutive days in January or February when the children are in the final class of elementary school (grade 8), and approximately 12 years old. The CITO data were collected by mail from teachers after informed consent was obtained from the parents, from the parents at age 12 of the twins, and/or by self report of the twins at age 14 or 16 years. There was a substantial agreement among the scores from different sources (correlations in the range of .93 to .99). Bartels et al. ${ }^{12}$ showed that CITO scores are moderately to highly correlated 
to IQ (correlations of .41, .50, .60, and .63 between CITO scores assessed at age 12 and IQ performance at age $5,7,10$, and 12 , respectively).

\section{Subjects included}

Survey data at age 12 and CITO scores were present for 4929 twins. Twins were excluded a) because of a handicap $(n=76)$; b) because they needed special education $(n=15) ; c)$ because twins were in different schools $(n=86) ; d)$ because twins were in different classes $(n=513)$, that represented different levels/grades; e) because data on classroom placement were missing or incomplete $(n=88)$; and $f)$ when the CITO score of one twin of a pair was missing $(n=145$, we have no information on the reason for the incomplete data), leaving 4006 twins (2003 twin pairs) in the sample. Of these 370 pairs were monozygotic male pairs (MZM), 269 were dizygotic male pairs (DZM), 469 were monozygotic female pairs (MZF), 302 were dizygotic female pairs (DZF) and 593 were dizygotic opposite sex pairs (DOS). Zygosity was determined by DNA or blood group polymorphisms for 702 pairs. For the remaining same sex twin pairs $(n=708)$, zygosity was based on questionnaire items. Zygosity determination using this questionnaire is $93 \%$ accurate. ${ }^{16}$

Thus the 2003 twin pairs we used in the analyses were healthy, typically developing 12-year-old (complete) twin pairs who were during primary school nonseparated (same school, same classroom), separated (same school, parallel class) and partly separated (partly same classroom, partly separated; there is no information about when and how long these twins were separated).

We had information on separation at the beginning of primary school (age 5) for 1768 twin pairs (for 233 pairs the survey at age 5 was not completed, for 2 pairs the survey was completed but the item on classroom separation was incomplete or missing). These 5-year-old twin pairs were at that time non-separated (same school, same classroom) or separated (same school, but parallel class). 


\section{Possible confounding factors}

Socio Economic Status (SES)

Data on Socio Economic Status (SES) from the survey mailed out when the twins were 3,7 and 10 years old were included in the analyses as van Leeuwen et al. ${ }^{3}$ reported less separated twins in low SES families. For respectively 1752 (assessed at age 3), 1762 (assessed at age 7) and 1766 (assessed at age 10) families SES data were available. As SES scores between age 3, 7 and 10 correlated highly (varying from 0.70 to 0.78 ), we used the SES score of age 7 when age 10 was not available and the SES score of age 3 when scores at age 7 and 10 were not available. This provided a SES score for 1972 families.

SES was based on a full description of the occupation of the parents and classified using a 5-point scale ( 1 =lowest, $5=$ highest), according to the system used by Statistics Netherlands. ${ }^{17}$ For the SES assessment at age 10 the EPG-classification scheme was used; this combines occupation with information on parental education. ${ }^{18}$ In both cases the highest SES score of the two parents determined the SES of the twin pair. The distribution of SES (from low to high) was $1 \%, 14 \%, 43 \%$, $27 \%$ and $15 \%$.

\section{Urbanization level}

Smaller villages may not offer the possibility to separate twins into parallel classes and therefore we tested whether urbanization level was associated with placement of twins. Urbanization level was determined by linking the participants zip codes at age 12 to the 2004 zip code information provided by Statistics Netherlands (Centraal Bureau voor de Statistiek, 2001). Statistics Netherlands manages a public national data base that covers a wide variety of societal and economical aspects of the Dutch society. For each zip code, Statistic Netherlands provides an urbanization 
level (scale of 0-4: very high, high, moderate, low, very low/none). When we had no data on zip codes at age 12 , we used data at age 14 or 16 . Data on urbanization were available for 1981 families. Missing data (22 families) were due to the fact that some families had moved to new areas with zip codes that were introduced after 2004. The distribution of urbanization (from low to high) was $29 \%, 23 \%, 17 \%, 23 \%$ and $8 \%$.

\section{Externalizing problems}

We examined whether externalizing problems at age 3, predicted separation at the beginning of the twin's school career. As part of the twins change in their school placement, we also examined externalizing problems at age 10 , as they possibly caused classroom separation later in school. Externalizing problems were assessed with a broad band scale of the Child Behavior Checklist ( $\mathrm{CBCL}$ ) completed by the mother. The Externalizing scale is based on the Aggressive and Rule Breaking Behavior subscales of the CBCL. ${ }^{19}$ Items are scored on a 3-point scale (i.e., not true (0), somewhat or sometimes true (1) and very true or often true (2); ratings are based on the occurrence of the behavior during the preceding 6 months.

The highest externalizing score within a twin of a pair was used. Data were available for 1682 complete twin pairs at age 3 (for 260 pairs the survey at age 3 was not completed, for 61 pairs the survey was completed but the items on externalizing problems were incomplete or missing for at least one twin). At age 10 there were externalizing problem scores for 1781 twin pairs (for 192 pairs the survey at age 10 was not completed, for 30 pairs the survey was completed but the items on externalizing problems were incomplete or missing for at least one twin).

\section{Statistical Analyses}


Data analyses were performed in SPSS 15.0 (SPSS Inc., Chicago, Illinois). First it was tested at family level whether SES and urbanization levels differed between twin pairs that shared a classroom and twin pairs who were in separate classrooms ( $\chi^{2}$-tests). In addition we tested the possibility that externalizing problems at age 3 differed between both groups at the start of school or later in school (one-way Anova; at age 12 with Bonferroni post-hoc comparisons as in this case data from three groups were analyzed: separated, non-separated and partly separated twins).

Secondly, we tested for significant differences in CITO scores between twins who shared a classroom the entire school period and twins who were in separate classrooms during their schooling. Because twin data consist of non-independent observations, for these analyses the Mixed Modeling option in SPSS was used, in which a correction for family dependency is applied. ${ }^{20,21}$ In the full model CITO scores were the dependent variable, while classroom separation, zygosity, sex, and an interaction effect between classroom separation and zygosity were included as fixed effects. Significant predictors for classroom separation at age 5 and at age 12 were also included as fixed effects. Family and zygosity status were incorporated in the model as random effects. Parameter estimation was by maximum likelihood. The type-I error rate was set at 0.01 to accommodate multiple testing.

\section{RESULTS}

\section{Descriptives}

The mean CITO score was 538.39 (8.39). Boys scored higher than girls (boys mean 539.13 (8.08), girls mean $537.74(8.60) ; F(1,4004)=27.862, p<.001)$, so we corrected for sex in the subsequent analyses. At age 12 most twin pairs (72\%) had shared a classroom during their schooling, $19 \%$ were in parallel classes most of the time and $9 \%$ of the mothers reported the twins had 'partly' shared a classroom. 
This pattern was the same in male and female, MZ and DZ twins. The history of separation (i.e., classroom placement at age 5 compared to age 12) showed that 96 pairs ( $8 \%$ ) that were non-separated at age 5 were separated at age 12 , and 187 pairs (37\%) that were separated at age 5 were non-separated at age 12 . Overall, $16 \%$ of twin pairs had changed their placement during primary school.

\section{Confounding factors}

Classroom separation at age 5 and at age 12 was significantly associated with SES $\left(\chi^{2}=22.909, \mathrm{df}=4, p<.001\right.$ and $\chi^{2}=38.028, \mathrm{df}=4, p<.001$, resp. $)$ and with urbanization $\left(\chi^{2}=55.257, \mathrm{df}=4, p<.001\right.$ and $\chi^{2}=80.118, \mathrm{df}=4, p<.001$, resp. $)$. Twins from lower SES families and lower urbanization levels were more likely to share a classroom. Also externalizing problems at age 3 were significantly associated with classroom separation at age $5(F(1,1583)=8.747, p=.003)$. Externalizing problems at age 10 and classroom separation at age 12 showed a trend for association $(F(2,1794)=3.939, p=.020)$ but the Bonferroni pot-hoc test showed that this reflected a difference between non-separated twins and partly separated twins $(p=.034)$ and not between non-separated and separated twins $(p=.341)$. Hence, the covariates that were used in the Linear Mixed Modeling procedure were urbanization, externalizing problems at age 3, and SES.

\section{Classroom separation and educational achievement}

Without adjusting for the confounding factors, a significant association between classroom separation and CITO scores was present (F $(2,1931)=7.200, p=.001)$. The effect size $(r)$ of classroom separation was 0.08. After adjusting for confounding effects, there was no significant effect of classroom separation on CITO scores $(F(2,1653)=1.985, p=.138)$, and the effect size decreased to 0.04. In addition, there was no interaction 
effect between classroom separation and zygosity $(F(8,686)=0.576$, $p=.798$ ), thus the association between classroom separation and CITO scores is the same for male and female $M Z$, male and female $D Z$ and opposite-sex twins.

Externalizing problems at age $3(B=-0.05, t(1659)=-3.40, p=0.001)$ and SES $(B=2.55, t(1647)=13.70, p<0.000)$ were significant covariates in the association between CITO scores and classroom separation.

Urbanization was not a significant confounder $(B=-0.07, t(1639)=-.54, p=$ $0.59)$. Effect sizes $(r)$ of the covariates were $0.08,0.32$ and 0.01 respectively.

Table 1 presents the mean CITO scores for separated and nonseparated twin pairs per zygosity group, before and after adjusting for significant covariates.

INSERT TABLE 1

\section{DISCUSSION}

This is the first study that investigated, as a function of male and female, MZ and DZ twin pairs, whether classroom separation has costs or benefits for their educational achievement. Twin pairs who had different educational levels due to other factors like repeating a class, handicaps or special education were excluded from the study. Thus, by keeping the cognitive level within pairs equal for twin pairs who were separated and who were not, we could focus on the true association between classroom placement and cognitive achievement, in typically developing twins. Our findings indicate that there is no difference in the educational achievement between twins who are together in a classroom and 
twins who are separated. Important covariates in the relation between classroom separation and CITO scores were socio-economic status and externalizing problems. Our results confirm those of Webbink et al. ${ }^{11}$ who also found no effect of classroom separation on cognitive abilities. We further showed that these results are the same for male and female, and $M Z$ and $D Z$ twins. The question whether separation has an influence on internalizing or externalizing problem behaviors of twins was already answered by van Leeuwen et al. $^{3}$; also for these outcomes there was no important effect of separation.

A remaining question is whether social development interacts with sharing a classroom with your co-twin. Because twins share their age and developmental needs, they do share friends more often than other siblings. ${ }^{22}$ An often used argument of schools in the Netherlands is that separation stimulates the individual development of cognition as well as in social contacts. In the current study a small subsample of 12 -year-old twins (from cohorts 1990-1992, N=169 pairs) answered the question 'do you share the same friends'. For twins who shared a classroom $74 \%$ reported 'yes, we share the same friends', $20 \%$ answered 'no, we have different friends', and $6 \%$ reported to share 'some friends'. For twins who were in separated classrooms this was respectively $25 \%, 50 \%$ and $25 \%$, and for twins who partly shared a classroom $50 \%, 38 \%$ and $12 \%$. These outcomes indicate that twins who share a classroom have more mutual friends. However, these results only apply to the primary school period. In this phase friendships might predominantly be based on classroom mates and therefore classroom separation explains the difference in the sharing of friends. Whether or not these shared friendships continue in life needs to be investigated.

\section{Methodological considerations}


Methodological strengths of this study were the prospective, longitudinal design, the large sample size and the correction for confounding effects like externalizing problems in the twins, and urbanization levels and SES of the family. The large sample size made it possible to test for interaction effects of separation with sex and zygosity. Lastly, the sample in this study was population based which makes the results representative of the normal twin population in the Netherlands and probably most Western countries.

This study has some limitations. We had no information on the reason why in some cases the CITO score of one twin was missing. However, inspection of the missing cases gave no indication for any systematic underlying factors that could explain these missing data. Furthermore, the data were of birth cohorts 1986 to 1993 ; it is possible that cognitive achievement differs between cohorts, but no cohort effects in CITO scores were found in the current analyses. Data on separation were derived from parental reports and not from a more objective source, like school records. A specific group in the analyses was the 'partly separated' group. Nine percent of the mothers reported that her twins had 'partly' been separated. We tested whether externalizing problems at age 10 might be a reason to separate twins later in school; this was not the case. One might think of other, for example practical reasons like moving of twin families, or expansion or reduction of a school population that enhances a separation or 'coming together' later in school.

\section{Conclusions}

Based on the current study one can conclude that there is no empirical evidence that cognitive achievement of twins depends on their classroom situation. Thus, our results support a policy in which there is no blanket ruling. However, based on factors indicated by the parents, 
teachers, or children themselves, there may be important reasons to separate twins at school, or not. We suggest therefore that classroom placement of twins should be based on each family's needs individually, in consultation with teachers, parents and children themselves. 


\section{WHAT IS ALREADY KNOWN ON THIS TOPIC}

Two previous studies on behavioral and emotional problems suggest that early separated twin pairs show more internalizing problems compared to non-separated twin pairs in the first grades of primary school. The effect sizes are small however, and the effects have disappeared at the end of primary school. One study reports no differences between separated or non-separated twin pairs on cognitive development but has no information on zygosity.

\section{WHAT THIS STUDY ADDS}

We replicate the findings on cognitive development using an educational achievement test that has high predictive value for future educational achievement. We find no differences in cognitive scores between separated and non-separated twin pairs. Socio economic status and externalizing problems interact with classroom separation and educational achievement in twins, but sex and zygositiy do not (i.e., the effects are the same in male and female, MZ, DZ and opposite-sex twins).

Contributors: All authors contributed towards the conception and design of the project, interpretation of the results, a critical review of the manuscript, and approved the final version. TJCP, MB and DIB designed the data analysis plan. TJCP performed the data analysis, wrote the manuscript, and is guarantor. CEM managed the data.

Funding: This work was supported by NWO 904-57-94, NWO/SPI 56-464-14192; NWO 480-04-004; NIMH, RO1 MH58799-03. TJCP is funded by Sophia Foundation for Scientific Research (SSWO, no. 562).

Competing interests: All authors declare that the answer to the questions on your competing interest form are all No and therefore have nothing to declare.

Ethical approval: The Netherlands Twin Register has received ethical approval from the VU University Medical Ethics Committee. 
Copyright: the Corresponding Author has the right to grant on behalf of all authors and does grant on behalf of all authors, an exclusive licence (or non exclusive for government employees) on a worldwide basis to the BMJ Publishing Group Ltd to permit this article (if accepted) to be published in BMJ editions and any other BMJPGL products and sublicences such use and exploit all subsidiary rights.

Provenance and peer review: Not commissioned; externally peer reviewed.

\section{Acknowledgements}

We thank all the participating twin families, and we thank Leo Beem for his helpful comments on the analyses. 


\section{Reference List}

1 Preedy P. Meeting the educational needs of preschool and primary aged twins and higher multiples. In: Sandbank AC, eds. Twin and Triplet Psychology. London: Routledge, 1999:70-99.

2 Geluk A, Hol J. Samen of apart? Meerlingkinderen naar school, peuterspeelzaal of kinderopvang [Together or apart? Multiples to school, playground or daycare]. NVOM brochure. 2001. Bergen, The Netherlands, NVOM (Dutch Society for Parents of Multiples).

3 van Leeuwen $M$, van den Berg SM, van Beijsterveldt TCEM, Boomsma DI. Effects of twin separation in primary school. Twin Res Hum Genet 2005;8:38491.

4 Hay DA. Together or apart? Twin Res 2004;7:iii-iiv.

5 Beauchamp HM, Brooks LJ. The perceptions, policy, and practice of educating twins: A review. Psychol Sch 2003;40:429-38.

6 Hay DA, Preedy P. Meeting the educational needs of multiple birth children. Early Hum Dev 2006;82:397-403.

7 Segal NL. Same or separate classrooms: a twin bill. Twin Res Hum Genet 2006;9:473-8.

8 Hall JG. Twinning. Lancet 2003;362:735-43.

9 Herskind AM, Basso O, Olsen J, Skytthe A, Christensen K. Is the natural twinning rate still declining? Epidemiology 2005;16:591-2.

10 Tully LA, Moffitt TE, Caspi A, Taylor A, Kiernan H, Andreou P. What effect does classroom separation have on twins' behavior, progress at school, and reading abilities? Twin Res 2004;7:115-24.

11 Webbink D, Hay D, Visscher PM. Does sharing the same class in school improve cognitive abilities of twins? Twin Res Hum Genet 2007;10:573-80.

12 Bartels M, Rietveld MJ, van Baal GC, Boomsma DI. Heritability of educational achievement in 12-year-olds and the overlap with cognitive ability. Twin Res 2002;5:544-53.

13 Boomsma DI, Vink JM, van Beijsterveldt TCEM, de Geus EJC, Beem AL, Mulder EJCM et al. Netherlands Twin Register: A focus on longitudinal research. Twin Res 2002;5:401-6.

14 Boomsma DI, de Geus EJ, Vink JM, Stubbe JH, Distel MA, Hottenga JJ et al. Netherlands Twin Register: from twins to twin families. Twin Res Hum Genet 2006;9:849-57. 
15 Bartels M, van Beijsterveldt CE, Derks EM, Stroet TM, Polderman TJ, Hudziak J] et al. Young Netherlands Twin Register (Y-NTR): a longitudinal multiple informant study of problem behavior. Twin Res Hum Genet 2007;10:3-11.

16 Rietveld MJ, van D, V, Bongers IL, Stroet TM, Slagboom PE, Boomsma DI. Zygosity diagnosis in young twins by parental report. Twin Res 2000;3:134-41.

17 Fengler M, Joung I, Mackenbach JP. Sociaal demongrafische kenmerken en gezondheid: Hun relatief belang en onderlinge relaties (Social demographic characteristics and health: Their relative importance and mutual relations). In: Mackenbach JP, Verkleij H, eds. Volksgezondheid Toekomst Verkenning 1997, II Gezondheidsverschillen. Maarssen, The Netherlands: Elsevier/De Tijdstroom, 1997:49-67.

18 Erikson R, Goldthorpe JH, Portocarero L. Intergenerational Class Mobility in 3 Western European Societies - England, France and Sweden. Br J Sociol $1979 ; 30: 415-41$.

19 Achenbach TM. Manual for the Child Behavior Checklist/4-18. Burlington, VT: University of Vermont, Department of Psychiatry, 1991.

20 Boomsma DI, van Beijsterveld TCEM, Beem AL, Hoekstra RA, Polderman TJC, Bartels $M$. Intelligence and birth order in boys and girls. Intelligence 2008;36:630-4.

21 Beem AL, Boomsma DI. Implementation of a combined association-linkage model for quantitative traits in linear mixed model procedures of statistical packages. Twin Res Hum Genet 2006;9:325-33.

22 Thorpe K, Danby S. Compromised or competent: analyzing twin children's social worlds. Twin Res Hum Genet 2006;9:90-4. 


\section{Table 1}

Mean scores of separated and non-separated MZ and DZ, male, female and opposite sex twins, with and without correction of SES and externalizing problem age 3

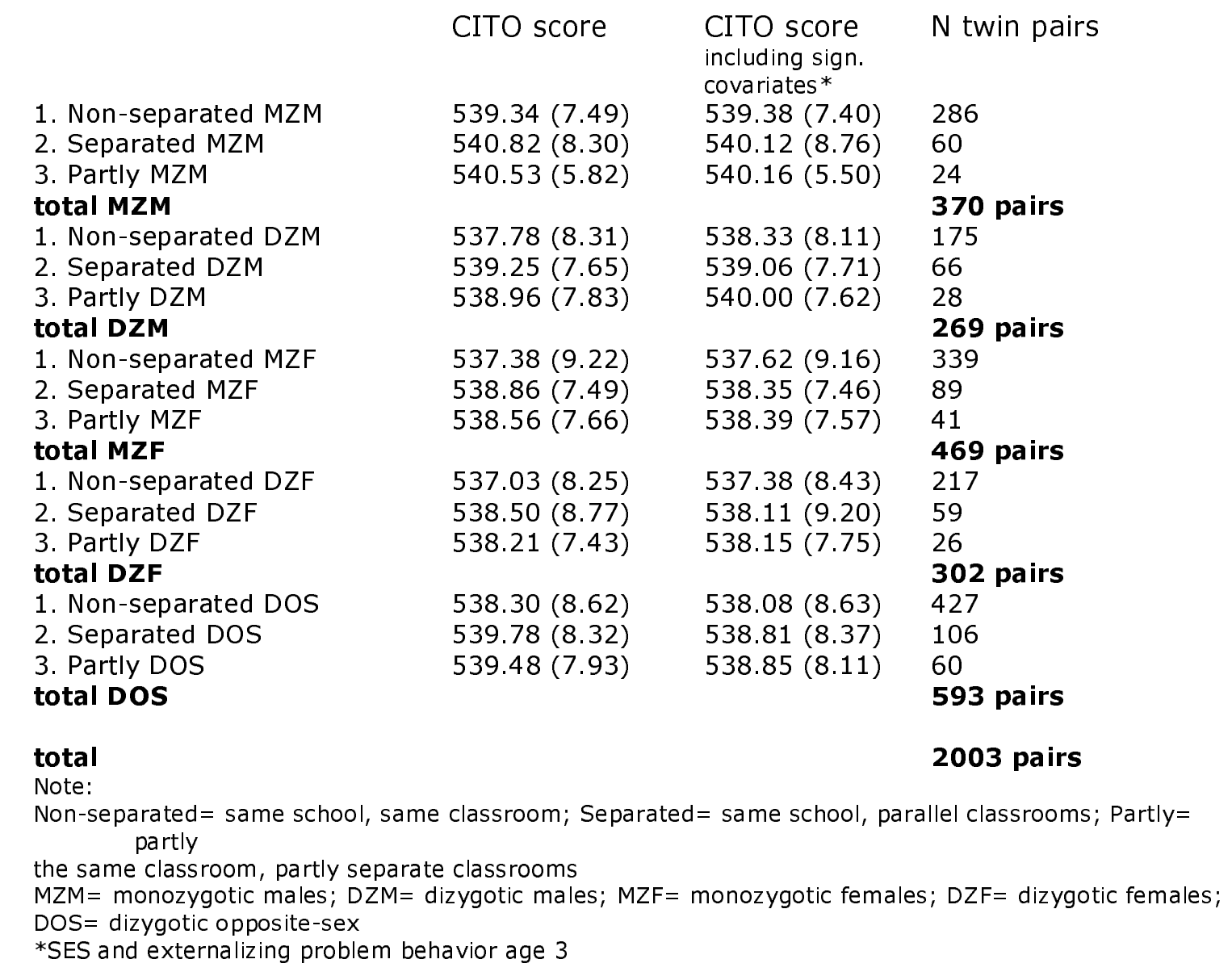

